\title{
Uso de Twitter por los alcaldes de las capitales de provincia españolas entre marzo y mayo de 2012
}

institucional.us.es/ambitos/

\author{
Patricia Ana López Pumar Universidad A Coruña \\ patypumar2@hotmail.com
}

\begin{abstract}
Internety las redes sociales son una gran herramienta de
\section{Resumen} comunicación. Twitter es una red de intercambio de opiniones personales y de interacción entre ciudadanos, por lo que los políticos deben saber usarla para interactuar con sus votantes. El objetivo es comprobar el uso que hacen los alcaldes de las capitales de provincia españolas de Twitter. Qué finalidades de comunicación tiene, cómo es su acceso, en qué medida sacan provecho o no y comprobar si han sabido adaptarse al nuevo modelo elector-consumidor.
\end{abstract}

\section{Palabras clave}

Twitter, red social, políticos, comunicación, interacción.

\begin{abstract}
Internet and social networks are a great tool of persuasion and communication. Twitter is a personal opinion exchange and interaction between citizens, so that politicians must learn to use it to interact with voters. The aim is to check the use made by mayors of Spanish provincial capitals Twitter. What purpose is communication, how to access, how far or take advantage and check if they have managed to adapt to the new voter-consumer model.
\end{abstract}

\section{Keywords}

Twitter, Social networking, political, communication, interaction.

\section{INTRODUCCIÓN}

La red social Twitter es usada por unos cien millones de personas en el mundo, con ella comparten sus pensamientos, y conocen en tiempo real las cosas que ocurren. Esa interacción entre personas ha derivado en una comunicación más amplia que engloba también a

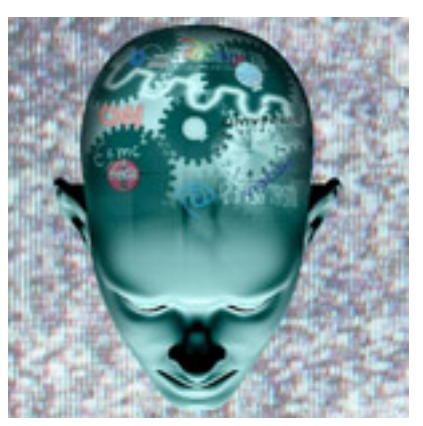
organizaciones, partidos políticos y empresas.

Desde el año 2008 las redes sociales y la política adquieren una gran importancia a través de la campaña de Barack Obama en Estados Unidos. A través de este estudio se busca ver el uso que hacen los políticos españoles de la red social Twitter, con qué frecuencia actualizan, cuál es su tipo de seguidores, si interactúan con ellos...

El análisis observa si los alcaldes tienen un Compromiso 2.0, si adaptan el marketing político y han hecho con su perfil e imagen un producto que vender a sus seguidores. Para el estudio se han tenido en cuenta las capitales de provincia españolas y las ciudades gallegas más importantes.

\section{MARCO TEÓRICO}

Kotler definió el marketing como "el proceso social y administrativo por el que los grupos e individuos satisfacen sus necesidades al crear e intercambiar bienes y servicios” (2008, ¿Qué es marketing?).

En el marketing se busca identificar y satisfacer las necesidades de las personas de forma rentable. Se utiliza en diez tipos de intercambios como son los bienes, los servicios, los acontecimientos, las experiencias, las 
personas, los lugares, las propiedades, las organizaciones, las informaciones y las ideas. Estas dos últimas son las que vamos a tratar en este trabajo.

Se debe ver a qué mercado se dirige, el de consumidores o el global, teniendo en cuenta el mercado virtual. Mohan Sawhney habla del cibermercado y el metamercado. Son mercados que ofrecen lo mismo que los convencionales pero que se fabrican en otros ámbitos, como puede ser el de Internet. Los cambios tecnológicos tienen mucho que ver en este aspecto, la revolución digital da paso a la Era de la Información que ofrece comunicaciones con una mejor dirección y que orientan los negocios hacia las redes electrónicas.

Michael Porter (1985) propone la cadena de valor para constituir un instrumento que mida el modo de generar más valor para los clientes de nuestro producto. Las empresas deben coordinar bien las actividades de cada departamento para captar clientes, gestionar las relaciones con los mismos y materializar la oferta.

Se debe valorar además el análisis DAFO. Externamente hay que ver las oportunidades y amenazas, lo que podemos conseguir con nuestro producto y lo que ofertan otras empresas del mercado: la capacidad de generar beneficios. En este caso una oportunidad de marketing es toda aquella necesidad de los compradores que una empresa puede satisfacer de modo rentable. En el análisis del entorno interno se valoran las fortalezas y debilidades, lo que tiene nuestro producto que no tienen los demás, lo que nos diferencia del resto o lo que nos hace vulnerables.

Una vez analizados estos apartados, la siguiente etapa es constituir los objetivos. Se debe formular una estrategia que nos muestre qué hacer para conseguirlo. Observar el entorno en que nos movemos, la edad de los consumidores, el nivel de educación, la posición geográfica... hacen posible la adaptación del producto para crear valor para el cliente y satisfacción. Tras esto es importante observar el comportamiento de los consumidores.

A la hora de elegir el medio para promocionar el producto entre las múltiples opciones que aparecen (anuncios prensa tradicional, marquesinas...) se debe elegir el diseño de un sitio web atractivo. Tenemos que analizar qué tipo de anuncios y promociones online queremos hacer, pueden ser banners (ventanas rectangulares pequeñas que contienen texto y a veces imágenes), un micrositio gestionado por la empresa (como es el caso de los seguros), la publicidad por contenidos o los anuncios por criterios de búsqueda.

Con todos estos pasos, una empresa puede diseñar un producto demandado, competitivo, y que satisfaga las necesidades de su público objetivo. En el lanzamiento del producto, la información sobre los clientes es primordial para garantizar el éxito del mismo. El paso principal de una empresa es conocer sus posibilidades y conocer cómo son y qué intereses tienen sus clientes potenciales.

Marketing político: Butler y Collins dicen que "se trata de la disciplina orientada a la creación y desarrollo de conceptos políticos relacionados con unos partidos o candidatos específicos que logren satisfacer tanto a determinados grupos electores como para que les otorguen su voto".

El profesor Teodoro Luque (1996) define como "un proceso de planificación con estudio previo del electorado que se concrete en una oferta programática y de personas, por tanto organizacional, que responda a las expectativas detectadas en el electorado desde una óptica ideológica".

Siendo más estrictos podemos situar su nacimiento en la época de griegos y romanos (aquí pensé relacionarlo con la opinión pública brevemente). Aunque si queremos centrarnos en el propio término en sí debemos ir a mediados del siglo XX en Estados Unidos. Stanley Kelley fue un analista político que supo ver el papel que jugaba este sistema a través de los políticos, quienes lo utilizaban para transmitir sus ideas y hacer que el impacto en el público fuese mayor.

En la Segunda Guerra Mundial ya se estaba empleando el marketing político para llegar a los ciudadanos. Hitler lo usó para convencerles de la necesidad de la guerra a través de la propaganda.

El primer presidente electo que supo utilizar de modo empresarial las armas y estrategias a su disposición fue Kennedy. Se sirvió de los asesores de imagen para conseguir la primera victoria electoral televisiva en el debate 
que mantuvo con Nixon. Este último en la campaña de 1968 copió el modelo Kennedy (el uso de los asesores) pudiendo así hablar de la primera etapa electoral donde se usó el marketing político de forma profesional.

Siguiendo con las elecciones americanas, pioneras en los diversos apartados electorales de todos los tiempos nos centramos en Regan. Utilizó la investigación de los mercados en campaña e introdujo otra parte del marketing tradicional a la hora de hacer política. Esto le sirvió para ser catalogado según las encuestas como uno de los tres mejores presidentes de Norteamérica.

Con estas nuevas introducciones, las ideas se añadieron a la lista de productos que podían entrar dentro del marketing, y lo convirtieron en una disciplina oficial que después sería estudiada.

Aunque estos casos son tomados como referencia e iniciación del marketing político, no se puede dejar pasar el caso estrella también del país norteamericano: Barack Obama. El presidente americano supo utilizar la conversación con el ciudadano. Manuel Castells dijo que no se puede entender Obama sin Internet.

El marketing aplicado a la política aparece porque hay un consumidor político. Se debe saber cuál es el producto político que queremos hacer llegar, cómo es la organización política y el mercado electoral.

Si en la Grecia antigua se reunían en el ágora para debatir y la gente acudía para estar informada, hoy en día también pasa esto. La diferencia la podemos situar en que hay que saber adaptarse a los núcleos sociales y los métodos que utilizan los ciudadanos.

Los consumidores políticos no obstante, ofrecen mucha información para poder diseñar campañas y que el político acceda a esa información de forma más rápida y precisa. El político debe saber utilizar a votante como ciudadano, pero también como consumidor.

Según Butler y Collins, el marketing político no sólo debe ver cómo desarrollar las campañas electorales, sino también cómo venderlas. Debe ser aplicado a todas las categorías dentro del partido político, hay que desarrollar además productos políticos, sacarlos al mercado... Buscar la demanda y constituir una oferta acorde para luego medir cómo se están cubriendo las necesidades del electorado.

El marketing político podemos verlo de forma más académica de la mano de Hughes y Dann "es una función de comunicación organizacional basada en un conjunto de procesos debidamente adaptada de la empresa a la arena política, para crear, comunicar y cumplir promesas de valor a los clientes y para gestionar las relaciones con esos clientes de forma que se obtenga beneficio para la organización política.

En este caso esos clientes son los votantes, y si en el marketing empresarial se busca obtener mayores beneficios, en el político no se trata solamente de ganar unas elecciones, sino también de ser seguidos y apoyados por nuevas partes de ese mercado de votantes o incluso convertirse en una oposición más fuerte y con más poder.

Una vez hemos definido el marketing político, debemos ver cómo crear un producto, en este caso un producto político.

Hay que ver qué es lo que el elector necesita y cómo hacer que llegue a él. La división de los políticos, ya no sólo a nivel nacional, sino regional y local (tema que trataremos en este trabajo). Además de esto debemos crear un producto de fácil asimilación así como directo y que nos devuelva el resultado acorde con el gasto realizado en el producto.

Para crear este producto hay que conocer a los votantes, no dirigirse a ellos de forma masificada como en un mitin, sino acotarlo a un grupo más reducido para asíllegar a todos y cada uno de ellos del modo en que lo requieren. Aquí hay que definir el targeting como ya hiciera Newman en su momento para la campaña de Bill Clinton. Segmentó a los votantes según sus necesidades e intenciones. Esto también deben tenerlo en cuenta nuestros políticos, delimitar geográficamente y demográficamente a sus votantes. Esto es un estudio previo de los asesores políticos, ya que no mueven los mismos intereses a la población de África o de Alemania.

Una vez seleccionadas las distintas clases de votantes, e político debe buscar su objetivo o target. A lo largo del 
tiempo siempre ha habido dos tipos, los votantes tradicionales y los indecisos. A los primeros hay que cuidarlos para que sigan depositando su papeleta a favor del político y a los segundos hay que convencerlos.

No deben los políticos en ningún caso tratar a los electores como ineptos, deben aplicar la inteligencia política y crear un producto potente y llevarlo hasta el final. Como ejemplo de fracaso podemos poner el eslogan ZP de José Luis Rodríguez Zapatero, y el "no nos mientas" que le pidió el electorado. Su decadencia llegó con el no reconocimiento a tiempo de la crisis, y ahí se demuestra que no supo administrar la inteligencia política para llegar al fin con su producto intacto. No midió bien los tiempos ni las actuaciones y esto provoca el rechazo de los votantes. El propio marketing político se volvió en su contra.

El objetivo que tiene esta inteligencia del marketing político es posicionar al representante o al político que debe ser elegido. El candidato nunca debería dejar de escuchar a sus votantes, para no perder así su posicionamiento.

Ahora nos vamos a centrar en el marketing político a nivel regional y local. Cómo los representantes en estos ámbitos deben saber innovar y adecuarse al ámbito en el que se mueven. Su producto debe ser fundamental para mejorar lo que ya existe y traer aires de innovación y progreso.

Redes sociales: Las redes sociales surgen gracias al auge de Internet. Son estructuras sociales online que sirven para comunicar a las personas entre sí a distancia. El inicio de las redes sociales o de la primera comunicación entre personas online la debemos remontar a 1995 cuando Randy Conrads crea classmates.com. Esta página web busca la comunicación entre antiguos compañeros de clase. En 2003 llega el turno de MySpace, Messenger y Facebook.

El término red social es designado por los antropólogos John Barnes y Elizabeth Bott (2006), acuñando lo de "social" por el hecho de que ese término también debía referirse a la pertenencia a un grupo social, no sólo por familia o amigos.

Las redes sociales presentan un gran peso para el marketing político: cuentan con un público objetivo muy segmentado. Con esto podemos ver un público que está expuesto a la campaña y su respuesta da un margen menor de error.

Las redes sociales tienen gran poder a la hora de transmitir información y pensamientos, por su rápido funcionamiento y por el reenvío masivo de mensajes.

Este tipo de modelo de comunicación permite interactuar y comunicarse con personas que ni siquiera se conocen, es un sistema abierto y cada seguidor aporta una parte.

Entre las distintas redes sociales podemos encontrar: MySpace, Facebook, Skype, Twitter...

Una vez delimitado el marketing en general y el político en particular debemos centrarnos en las redes sociales su uso y su relación con la comunicación política.

En primer lugar haremos mención a los blogs, pioneros en la comunicación política 2.0., y que después dieron paso a Twitter o Facebook.

Un weblog "es un sitio web que se compone de entradas individuales llamadas anotaciones o historias dispuestas en orden cronológico inverso. Cada historia publicada queda archivada con su propia dirección URL a modo de enlace permanente, así como con la fecha y hora de su publicación” (Orihuela, 2006, página 34).

Desde el año 1997 se utiliza el término weblog, en español aparece en el año 2005 en el Diccionario Panhispánico de Dudas como "sitio electrónico personal, actualizado con mucha frecuencia, donde alguien escribe a modo de diario o sobre temas que despiertan su interés, y donde quedan recopilados asimismo los comentarios que esos textos suscitan en sus lectores".

A pesar de que en los blogs también aparecen noticias publicadas no son sustitutos de los medios tradicionales, sino complementarios. Estos medios sociales tienen una actitud más crítica y personal que los tradicionales, se 
basan en el saber colectivo frente al de un solo redactor.

Estos medios sociales han ido evolucionando. En un principio aparece la blogosfera 1.0 y va desde la primera publicación de una página web en el año 1992 hasta el lanzamiento de Blogger en 1999. Son páginas web muy simples, con dos columnas donde se ponen las entradas y los enlaces. El siguiente paso es la blogosfera 2.0 que va desde 1999 hasta 2004. En este período los blogs se convierten en un fenómeno masivo. Comienzan a introducir imágenes y aparece el primer intento de insertar sonido. La última etapa es la blogosfera 3.0, que empieza en el año 2005. Los podcast van afianzándose y es momento de empezar a incluir los archivos de video en el propio blog.

Los blogs han llegado a todos los ámbitos: empresas, educación y también política. La política 2.0 o democracia extrema es una de las consecuencias de la introducción de los blogs en este ámbito. Los ciudadanos comienzan a opinar a través de estos mecanismos sobre política, lo que les devuelve el control y la iniciativa sobre la cosa pública.

El Prestige y los atentados del 11 de marzo marcan un antes y un después en el uso de los blogs en España. Los ciudadanos comienzan a recuperar el interés por formar parte de la política y dan su opinión a través de estos medios sociales. Con los atentados del 11 de marzo dentro del mundo de la información se puede considerar a los periodistas como las primeras víctimas. Los ciudadanos tenían ansias de saber, y se molestaron (especialmente los jóvenes) por buscar la información que les era negada. La desconfianza hacia los medios tradicionales se multiplicó y la gente los veía como muy alineados políticamente hablando.

Este interés de información cambia la esencia de nuestra democracia, ya no nos sirve la representativa, sino que queremos una en la que se pueda deliberar, es lo que Mitch Ratcliffe y Jon Lebkowsky llamaron democracia extrema. Democracia en la que se descentraliza el debate y las comunidades de ciudadanos pueden participar a través de su opinión, aumenta así su participación.

El futuro de los blogs no parece tener fin. Los usuarios ya se han acostumbrado a poder poner en la web sus opiniones ayudándose de la información de los medios tradicionales. No es raro ver a periodistas que poseen un blog personal donde dan su opinión.

Twitter: es una red social diseñada en un principio para que la gente a través de una plataforma web pudiese mandar SMS a una cuenta para ser distribuido a otros usuarios. Las bases de este modelo de comunicación son la sencillez de sus mensajes (hasta 140 caracteres), la movilidad en la producción y el consumo de los mensajes, la articulación entre mensajes y web y las relaciones de los usuarios.

Al igual que todas las redes sociales, Twitter comenzó siendo un sistema de mensajería creado para la comunicación entre los empleados de la empresa Odeo. El 21 de marzo de 2006 se publicó el primer mensaje en la plataforma que se llamaba Twttr. En junio de ese mismo año la empresa se abre al público con el nombre de Twitter.

España es el tercer país del mundo que más usa Twitter, cuenta con casi 8 millones de usuarios de esta red social. Su uso en España comenzó siendo discreto, pero pronto empezó a ser usado por empresas e incluso políticos. Para los usuarios supone un modo rápido y directo de hablar sobre temas de actualidad. Actualmente las noticias llegan antes a Twitter que a muchos medios de comunicación.

Esta red social es asimétrica, donde las relaciones son optativas y no debe haber consentimiento mutuo entre las personas que la utilizan; breve, ya que los mensajes están limitados a 140 caracteres en cada mensaje; descentralizada, está construido por las decisiones de cada usuario; global, disponible en varias lenguas y países...

Una vez sabidos todos los caracteres propios de esta red social hay que preocuparse por mantener a los seguidores. El perfil para ello debe ser actualizado, incluir novedades y responder a las cuestiones que se nos puedan plantear.

Aparecen cuatro desafíos para los políticos que están en esta red social. Uno de ellos es superar el espacio de 
la campaña electoral, es decir, usarlo más allá de la campaña. Evitar hacer propaganda, administrar personalmente la cuenta y no dejarlo en manos de un equipo de gestión y ser transparentes.

Con estos nuevos medios sociales a los políticos se les presenta una gran novedad para hacer que los ciudadanos participen más. Además de esto, la red social también ofrece mayor transparencia y control de lo que hacen los políticos dentro y fuera de la campaña.

El uso de las redes sociales ha cambiado por completo la forma de comunicarse los políticos y los votantes. Los primeros han de ayudarse del marketing político para poder poner en circulación un producto rentable y que les reporte beneficios.

El éxito de las redes sociales y el cambio en cuanto a lo que el discurso político se refiere hacen necesario el estudio de estos medios y sus consecuencias.

En la democracia actual existe un distanciamiento entre representantes y representados y vamos a analizar y ver si realmente gracias a las redes sociales este distanciamiento está disminuyendo. Este análisis observa que porcentaje de ciudadanos sobre el total de electores siguen a cada alcalde, y las facilidades o no que pone cada alcalde para contactar con él a través d Twitter.

Conocer el uso de las redes sociales en este ámbito político hace que se pueda observar cómo son las relaciones de proximidad entre alcaldes y ciudadanos. Los alcaldes en las redes sociales provocan una sensación de cercanía, ya que accediendo a su perfil podemos contactar con ellos de forma directa, y no pidiendo citas. Pasan de ser actores que hacen su función en los mítines y los medios tradicionales a ser social media. Se involucran en las nuevas tecnologías y se adaptan a las costumbres de sus votantes. Se modernizan para llegar a ellos de forma más directa y darles la sensación de trato directo y no masificado.

\section{METODOLOGÍA}

A través de una bibliografía amplia se busca saber qué es el marketing, las redes sociales y cómo es su funcionamiento en conjunto. Se toma como fuente de consulta la página web de cada Ayuntamiento y Twitter, se observa cada alcalde, si está en la red social, si se trata de un perfil verdadero o falso y se valora si hay acceso a su Twitter personal desde la página del Ayuntamiento.

Una de las modalidades de análisis empleada es la comparativa. Analizando uno por uno los alcaldes de las capitales de las provincias españolas y las tres ciudades más importantes de Galicia (Ferrol, Vigo y Santiago de Compostela), para después comparar el modo de usar Twitter por parte de cada uno de ellos. También se tienen en cuenta los seguidores, valorándolo en función del número de habitantes y el acceso a Internet en dicha ciudad.

Se emplea el método exploratorio, cada alcalde individualmente por medio de su perfil para poder ver su interacción con los ciudadanos y el nivel de involucración en su cuenta, cómo y para qué la utiliza.

El análisis es cuantitativo para ver cuántos son los alcaldes que utilizan esta red social. Cualitativamente se ve en qué modo la utilizan, cuáles son sus seguidores, a quién siguen, cómo twittean...

El estudio se hace entre marzo de 2012 y mayo de 2012. No obstante para aquellos perfiles que no son actualizados con tanta asiduidad se verá cuál fue la fecha de su último tweet.

El uso de estas modalidades responde a la necesidad de observar y comparar a cada individuo de forma individual y en relación con su entorno para así determinar su modo de usar Twitter y cómo mejorarlo.

\section{ANÁLISIS DE DATOS}

La hipótesis principal es que la acción política local en la red social es muy baja. Las preguntas que se plantean son: ¿quiénes son los alcaldes de las principales provincias españolas (más las 3 ciudades más importantes de Galicia) que emplean Twitter?, ¿en qué modo utilizan esta red social?, si lo hacen para informar simplemente, si es para cumplir con el compromiso de estar por estar o si hay interacción con los ciudadanos. Twitter ha 
revolucionado las redes sociales por su rapidez y eficacia, por lo que vamos a comprobar que en política ocurre lo mismo y se usa del mismo modo.

Se toma Twitter como una red social horizontal, dirigida a todo tipo de usuario y sin temática predefinida, que se adapta a lo que este "de moda" en ese momento. Admite una participación libre por lo tanto cada ciudadano puede así, en teoría, mostrar sus intereses, sus dudas... a su alcalde.

Los españoles están muy presentes es esta red social, por lo que los alcaldes de las capitales de provincia también deben estarlo. Han de interactuar con los votantes para así conseguir de forma más económica lo que les ofrecen otros modelos de hacer campaña como es la televisión.

Se puede afirmar que las ciudades que sobresalen en el número de electores-seguidores y el número de habitantes totales son Gerona y Toledo con un 7,59\% y 7,05\% respectivamente. Por otro lado los perfiles que menos seguidores poseen son los de Las Palmas de Gran Canaria y Vigo. Tomando como referencia los 10 primeros se observa que a excepción de Cádiz y Sevilla el resto de provincias se encuentran en el centro norte del país. En los 10 últimos puestos observamos que la mitad de los perfiles pertenecen al norte de España y la otra mitad al sur. De los 10 primeros alcaldes con más seguidores según su población 6 pertenecen al PSOE, 3 al PP y 1 a otros partidos. Poseen más seguidores los alcaldes del PSOE, que de los demás partidos.

En cuanto al número de tweets, son más los alcaldes del Partido Popular los que actualizan con mayor constancia su cuenta personal, en el PSOE son 2 y otros 2 en otros partidos.

De las ciudades más pobladas de España sólo Sevilla se encuentra entre las 10 primeras, Barcelona ocupa el puesto número 19 sobre 33 alcaldes con cuenta en Twitter y la alcaldesa de Madrid ni siquiera posee cuenta en la red social.

En cuanto al número de tweets, Barcelona y Sevilla ocupan las primeras posiciones, seguidas de Santa Cruz de Tenerife y Lérida. De las 10 primeras ciudades 6 de ellas pertenecen a la parte centro-norte de España, mientras que 4 son del sur.

Con estos resultados se observa que en el centro-norte de España los alcaldes de las principales provincias españolas usan más la red social que en el sur del país. En el número de tweets, sólo se encuentran 4 provincias del norte de España como las que menos twittean sus alcaldes.

El uso que hacen dichos alcaldes de las redes sociales la mayor parte lo hace institucional y políticamente. Son 27 los alcaldes que hacen uso de la red social para asuntos institucionales, y 5 de ellos políticos. En cuanto al uso personal son 21 los que la emplean con ese fin.

Si se observa por partidos políticos, el Partido Popular es el que mayor uso político e institucional hace de los perfiles de sus alcaldes.

No sólo es cuestión de los alcaldes aparecer en la red social y tener un Compromiso 2.0 sino que los ciudadanos también han de tener interés en seguir al alcalde de su localidad. Viendo la relación electoresseguidores se puede afirmar que a pesar de que algunos alcaldes hacen actualizaciones diarias no poseen gran cantidad o número de seguidores.

Por tanto no se puede sentenciar con base a este aspecto que los alcaldes no tienen un Compromiso 2.0, sino que los ciudadanos tampoco muestran interés por seguirles en la red social e interactuar con ellos.

Dentro de la propia red social podemos ver que hay ciudades como Barcelona donde las actualizaciones son diarias y que posee gran cantidad de tweets y otras donde apenas hay 70 comentarios. Casi con toda seguridad en España a excepción de dos o tres perfiles más personales los alcaldes emplean esta red social para hacer campaña. No hacen uso de ella sino abuso, un abuso en beneficio propio y sin ningún tipo de criterio, no usan el marketing político. No se ve un estudio de las personas a las que va dirigida, ni que el uso sea para ganar votantes, se conforma con aparecer en ella, están por estar, porque es lo que marca la época en la que vivimos.

\section{CONCLUSIONES}


Los políticos españoles no han sabido adaptarse a las redes sociales. Todavía les queda mucho que aprender en este aspecto, deben usarlas en beneficio propio para llegar a más población. La sociedad está en Twitter y exige estar ahí. No se preocupan por saber cómo es esa población a la que se dirigen, que les interesa... no hacen un estudio de la misma para después aplicar una forma de actuar en la red social.

Hay 3 tipos de políticos en Twitter, los que lo utilizan de forma personal, los que lo hacen de modo institucional y los que lo emplean de modo político y de campaña. Además su uso no es en más del 13 de los casos asiduo, las actualizaciones sólo son diarias o semanales en este porcentaje, y además en casi la mitad de estos casos es realizado no sólo por el alcalde, sino también por su grupo político.

En cuanto a las diferentes franjas geográficas del país en la zona centro-norte los alcaldes hacen mayor uso de la red social y postean mayor número de tweets que en el sur del país. En las grandes ciudades los alcaldes poseen menor número de seguidores en relación con el número de habitantes que en las ciudades más pequeñas. En referencia a los partidos políticos, el PSOE se encentra en más posiciones dentro de los 10 primeros en cuanto al número de seguidores.

Se debe utilizar un punto común entre una empresa y un político: ambos tienen compradores fieles, compradores eventuales (a veces votan y a veces no) y no compradores.

Los primeros siempre acuden a la misma empresa ocurran las circunstancias que ocurra, los segundos valoran otros apartados para ejercer el voto y los últimos se definen así bien porque votan a otro partido o bien porque están desencantados con el sistema y deciden no ir a "comprar".

El político o partidos políticos como cualquier otra organización la peor situación que pueden vivir es perder clientes a favor de otro partido o que directamente estos no vayan a votar.

Internet y las redes sociales son una gran herramienta si se saben utilizar, deben crear una imagen, y un producto que vender en la misma. Si se habla de Twitter como es el caso también se debe ver que es una red de intercambio de opiniones personales, y de interacción entre los ciudadanos por lo que los políticos han de usarla asiduamente e interactuar con sus votantes.

Como dijo el blogger Chris Pirillo: "Twitter es un buen sitio para decirle al mundo lo que estás pensando antes de que hayas tenido la oportunidad de pensarlo".

\section{BIBLIOGRAFÍA}

Alonso, M.A., Adell, A. (2011): Marketing Político 2.0. Gestión 2000: Barcelona.

Berrocal, S. (2003): Comunicación política en televisión y nuevos medios. Ariel Comunicación: Barcelona.

Del Rey Morató, J. (2007): Comunicación política, Internet y campañas electorales. Tecnos: Madrid.

Kotler,P y L.Keller, K. (2008): Dirección de Marketing. Pearson: Madrid.

Luque, T. (1996): Marketing político: un análisis del intercambio político. Editorial Ariel: Barcelona.

Butler, P y Collins, N. (1993): Campaigns, candidates and marketing in Ireland. Politics, vol.13, pp. 3-8.

Newman, B. (1994): The marketing of the president: Political marketing as campaign strategy. London: Sage.

Orihuela, J.L. (2011): Mundo Twitter. Barcelona: Alienta Editorial.

Pérez Barber, V. (2010): El político en la red social. Alicante: ECU.

Requena Santos, F. (2003): Análisis de las redes sociales: Orígenes, teorías y aplicaciones. Madrid: CIS.

Túñez, M. y Sixto, J. (2011): Redes sociales, política y Compromiso 2.0: La comunicación de los diputados españoles en Facebook, en Revista Latina de Comunicación Social, 66. La Laguna (Tenerife). 


\section{Breve semblanza de la autora:}

Patricia Ana López Pumar es licenciada en Periodismo por la Universidad Complutense de Madrid (2011), Máster en Comunicación e Industrias Creativas por la Universidad de Santiago de Compostela (2012) y Máster en Gestión y Políticas Públicas por la Universidad de A Coruña (2013). Doctorando en la Universidade Da Coruña.

Ámbitos. Revista Internacional de Comunicación, n.26, año 2014, tercer trimestre (otoño). 